\title{
Norm Kadro Çalışmalarının Üniversitelerde Uygulanabilirliği: Nitel bir Araştırma
}

\author{
Kürşad YILMAZ* \\ Güven ÖZDEM**
}

ÖZ: Norm kadro çalışmaları örgütlerin amaçlarını etkin ve verimli bir şekilde yerine getirebilmeleri için uygulanmaktadır. Bu çalışmaların en önemli amaçlarından birisi, görevlerin yerine getirilmesi için gereken kadronun nitelik ve sayısının belirlenmesidir. Burada önemli olan, amaçların gerçekleştirilmesi ve bu yöndeki işlerin yapılması için gerekli olan ideal kadronun belirlenmesidir. Norm kadro çalışmaları bütün kamu kurumlarında olduğu gibi üniversitelerde de yapılmaya çalışılmaktadır. Ancak üniversitelerin norm kadrolarının belirlenmesi diğer kamu kuruluşlarındaki kadar kolay görülmemektedir. $\mathrm{Bu}$ çalışmada, bu amaçla daha önce norm kadro çalışması yapmış ve yapılan çalışmayı değerlendirmiş olan öğretim üyeleri ile görüşmeler yapılmış, bunlar kaydedilmiş ve çözümlenmiştir.

Anahtar Kelimeler: Norm Kadro, Üniversiteler, Akademisyenler

The Practicability of Norm Staff Studies in Universities:

\section{A Qualitative Research}

\begin{abstract}
Norm staff studies are being applied for organizations to perform their aims actively and productively. One of the most important targets of this study is to determine the quality and number of staff needed for the works done. The important point is to determine the ideal staff for doing the jobs in this route for realizing the aims. Norm staff studies are being tried to carry out in universities like in all public association. However, it seems not easy to determine the norm staff of universities as the other public associations. In this study,
\end{abstract}

\footnotetext{
* Arş. Gör. Ankara Üniversitesi Eğitim Bilimleri Fakültesi

** Arş. Gör. Ankara Üniversitesi Eğitim Bilimleri Fakültesi
} 
interviews were held with the academicians who made and evaluated norm staff study, in the end recorded interviews analyzed.

Keywords: Norm Staff, University, Academicians

\section{GİRIŞ}

Norm kadro çalışmaları örgütlerin görevlerini etkin ve verimli bir şekilde yerine getirebilmeleri için uygulanan çalışmalardır. Bu çalışmaların en önemli amaçlarından birisi, görevlerin yerine getirilmesi için gereken kadronun nitelik ve sayısının belirlenmesidir. Bu amaçla yapılan norm kadro çalışmaları, örgüt içerisinde yer alan görevlerin gerçekleştirilebilmesi için gerekli olan, ideal kadronun nitelik ve nicelik yönüyle belirlenmesidir. Burada önemli olan amaçların gerçekleştirilmesi ve bu yöndeki işlerin yapılması için gerekli olan ideal kadronun yani, olması gerekenden ne daha az, ne de daha fazla kadronun belirlenmesidir. Norm kadro çalışmaları bütün kamu kurumlarında olduğu gibi üniversitelerde de yapılmaya çalışılmaktadır. Ancak yapılan işin niteliği açısından, üniversiteler diğer kamu kuruluşlarından çok farklı bir niteliğe sahiptir. Bu farklılığın temel sebebi üniversitelerde görev yapan akademik işgörenlerin norm kadrolarının saptanmasının diğer memurlar kadar kolay görünmemesidir. Çünkü, akademik işgörenlerin çalışma saatlerini mesai saatleri ile sınırlamak mümkün değildir. Akademik işgörenler işlerinin niteliği gereği mesai saatleri dışında, hafta sonlarında, tatillerde veya gece evlerinde çalışmakta ve çalışabilmektedirler. Bundan dolayı öğretim üyelerinin görev yaptığı kurumlarda yapılacak olan norm kadro çalışmalarında ne gibi zorluklar ile karşılaşılabileceğinin belirlenmesinde fayda vardır. Bu çalışmada, bu amaçla daha önce norm kadro çalışması yapmış ve yapılan çalışmayı değerlendirmiş olan öğretim üyeleri ile görüşmeler yapılmıştır.

\section{Problem}

Norm kadro, bir örgütte, benzer nitelikteki ödevlerden oluşan görevlerin yürütülmesine olanak veren yapının, amaca göre belli bir tip halinde düzenlenmesidir. Norm kadro düzenlemelerinde, benzer nitelikteki ödevlerin organik gelişim esasına göre sıralanması ve mümkün ise kendi aralarında sinıflandırılarak yazılması gerekmektedir (Kalkandelen, 1997).

Norm kadro, kamu kurum ve kuruluşlarının, görevlerini etkin ve verimli bir şekilde yerine getirebilmeleri için, olması gerekenden ne daha az, ne de daha fazla kadronun nitelik ve nicelik yönüyle saptanmasıdır (Acar, 2000; Acar, 2001).

Norm kadro çalışmaları, amaçların gerçekleştirilmesine yardımcı olmakta, işgören ihtiyacının tahminine, işgörenlerin atanmasına, değerlendirilmesine, kademe ilerlemesine, derece yükseltilmesinden 
emekliliğe kadar uzanan tüm işgören işlemlerinin yapılmasında alt yapı hizmetini görmektedir. Norm kadro süreci, örgüt çözümlemesi, iş çözümlemesi, görev tanımları ve görev gerekleri ile norm kadro sayısının belirlenmesi aşamalarından oluşmaktadır (Kalkandelen, 1997). Yukarıda sıralanan aşamalardan da görülebileceği gibi norm kadro çalışmalarının başarılı bir şekilde yapılabilmesi için örgüt çözümlemesinin mutlaka yapılması gerekmektedir.

Kalkandelen'in (1997) belirtmiş olduğu norm kadro çalışmalarının yararlarını şöyle özetlemek mümkündür. Norm kadro çalışmaları; kadro unvanlarına açıklık getirir ve değişik anlayışları önler, tarafsız yönetimin sağlam temellere dayandırılmasında yapısal eleman hizmetini görür, eşit işe eşit aylık veya ücret sisteminin kurulmasına yardım eder, işgören ihtiyaçlarının tahmin edilmesine ve saptanmasına, işgören giderlerinin en uygun biçimde saptanmasına, kadro gereklerine uygun niteliklerde işgörenlerin bulunup ișe alınmasına, kadro gereklerine uygun nitelikli işgörenin yetiştirilmesine, işgörenlerin eğitim ihtiyacının saptanmasına olanak verir.

Yukarıda sıralanan yararları çoğaltmak mümkündür. Ancak, norm kadro çalışmaları kayırmayı engellemede ve yeterliğe dayalı bir işgören yönetiminin oluşturulmasında önemli bir yere sahip görülmektedir. Norm kadro çalışmaları nitelikli işgörenlerin alınmasında, bu işgörenlerin yetiştirilmesinde ve değerlendirilmesinde de çok önemli yararlar sağlamaktadır. Ayrıca demokratik bir yönetim anlayışının yerleştirilmesinde de norm kadro çalışmaları önemli bir güce sahiptir.

Acar (2000) norm kadro çalışmalarının getireceği katkıları ise şöyle özetlemektedir. Norm kadro çalışmaları, kaynakların yerinde ve verimli kullanılmasını ve çağdaş normlara ulaşılmasını sağlayacaktır. Norm kadro çalışmaları, firsat ve olanak eşitliğini sağlayarak demokratikleşmeye katkıda bulunacak, işgören değerlendirmelerinin yansız, adil, nitelikli, verimli ve ekonomik gereklere uygun biçimde yürütülmesine katkıda bulunacaktır.

Yukarıda belirtilen katkıları sağlayacağı düşünülen norm kadro çalışmaları ile ilgili olarak Bakanlar Kurulu'nun 06.11.2000 tarih ve 2000/1658 sayılı kararı ile kabul edilen "Kamu Kurum ve Kuruluşlarınca Yapılacak Norm Kadro Çalışmalarında Uygulanacak Usul ve Esaslar" 20.12.2000 tarih ve 24266 sayılı Resmi Gazetede yayımlanarak yürürlüğe girmiştir. Bu kararın amacı, kamu kaynaklarının verimli kullanılması, kamu hizmetlerinin gerektirdiği unvanda, nitelikte ve sayıda işgören istihdamının sağlanabilmesi amacıyla norm kadroların belirlenmesidir (Karakütük, 2003).

Yayımlanan bu kararda norm kadro çalışmalarında göz önünde bulundurulması gereken ilkeler de belirlenmiştir. Resmi Gazetede yayımlanan Bakanlar Kurulu Kararı'nın 10. Maddesinde özetle; hazırlanan 
norm kadro çalışmaları Maliye Bakanlığı ve Başbakanlık Devlet Personel Başkanlığı ile ilgili kurum (Mahalli idareler için İçişleri Bakanlığı) temsilcilerinden oluşturulan komisyon tarafindan konuyla ilgili mevzuat çerçevesinde incelenerek norm kadro çalışmaları sonuçlandırılır, denilmektedir. Kararın 11. Maddesinde ise; norm kadro çalışmaları sonuçlandırılmadıkça veya kanunla milletlerarası anlaşmalarla veya Bakanlar Kurulu kararı ile öngörülmedikçe, kurum ve kuruluşlar kadro ihdas1 ve serbest birakma talebinde bulunamazlar, denilmektedir.

Yukarıda görüldüğü gibi Bakanlar Kurulu kararına göre, hazırlanan norm kadro çalışmaları resmi kurumlara teslim edilecek ve bu çalışmalar komisyon tarafından incelenecektir. Ayrıca bu çalışmalar belirlenen takvime göre tamamlanmadığı taktirde, kurum ve kuruluşlar kadro ihdasında ve serbest birakma talebinde bulunamayacaklardır.

Norm kadro çalışmalarının belli bir süre içerisinde tamamlanabilmesi için Başbakanlık Devlet Personel Başkanlığı ve Maliye Bakanlığ tarafından kurumlar düzeyinde bir takvim belirlenmiştir. $\mathrm{Bu}$ takvim ile ilgili olarak Başbakanlığın 2001/39 sayılı genelgesi 11.07.2001 tarih ve 24459 sayılı Resmi Gazetede yayımlanmıştır. Bu takvime göre üniversitelerin norm kadro çalışmalarını 15.07.2001 ile 31.12.2003 arasında değişen tarihlerde tamamlamaları gerekmektedir.

Norm kadro çalışmalarını, sadece memurların görev yaptığı kurumlarda veya iş tanımının kolaylıkla yapılabildiği kurumlarda uygulamak kolay görülmektedir. Ancak, norm kadro çalışmalarını üniversitelerde yürütmenin bir takım zorlukları vardır. Başka bir ifade ile üniversitelerde norm kadro çalışmalarının yapılması diğer kurumlardaki kadar kolay görülmemektedir. Çünkü üniversitelerin kendilerine özgü özellikleri ve burada görev yapan akademik işgörenlerin de diğer işgörenlerden farklı çalışma koşulları bulunmaktadır.

2547 sayılı Yükseköğretim Yasası üniversiteyi, bilimsel özerkliğe ve kamu tüzel kişiliğine sahip yüksek düzeyde eğitim-öğretim, bilimsel araştırma, yayın ve danışmanlık yapan; fakülte, enstitü, yüksekokul ve benzeri kuruluş ve birimlerden oluşan bir yükseköğretim kurumu olarak tanımlamaktadır.

Üniversitelerin işlevleri öğretim yapmak, araştırma ve yayın yapmak biçiminde özetlenebilmektedir. Araştırma etkinliklerinin, üniversitenin işlevleri arasında yer alması, üniversitede bilimsel araştırma etkinlikleri ile öğretimin ayrılmaz bir bütünlüğe sahip olması sonucunu ortaya çıkarmıştır (Karakütük, 2002). Ayrıca araştırma ve öğretim, üniversite öğretim elemanlarının kimliklerinin ayrılmaz bir parçası (Rosovsky, 1994) olarak görülmektedir. Ayrıca üniversitelerin toplum hizmeti de bu bağlamda düşünülebilir. 
2547 sayılı Yükseköğretim Yasasında öğretim üyelerinin görevleri; eğitim-öğretim yapmak, proje hazırlıklarını ve seminerleri yönetmek, bilimsel araştırmalar ve yayımlar yapmak, öğrencilere rehberlik etmek, yetkili organlarca verilecek görevleri yapmak ve yasa ile verilen diğer görevleri yapmak şeklinde özetlenebilir. Yasada da görüldüğü üzere öğretim üyelerinin görev tanımlarının yapılabilmesinin bir takım zorlukları bulunmaktadır. Öğretim üyesi mesai saatleri içinde eğitim-öğretim, mesai saatleri dışında da bilimsel araştırmalar yapabilir. Ayrıca yasayla öğretim üyelerine "yetkili organlarca verilecek görevleri yapmak" gibi sınırları ve süresi çizilemeyecek görevler verilmiştir.

Bilim insanı ise evrendeki olay ve olguları inceleyen, onların altında yatan gizemin kaynağını sorgulayan ve bu gizemin nedenlerini anlayan ve anladığını kitlelerin anlayabileceği bir şekilde yayın yolu ile duyuran kişi olarak tanımlanmaktadır. Ayrıca bilim insanı anlamış olduğu doğal gizemi, yaşamı daha da kolaylaştıracak şekilde insanlığın yararına sunan kişidir (Ortaş, 2002).

Bilimsel araştırmalar, bilimsel araştırma yapan kişilerin, insana ve doğaya ilişkin bilgileri ortaya çıkarma yönündeki çabalarını, etkinliklerini ve uygulamalarını içermektedir. Bilimsel araştırmaların sonuçlarını bilim insanı sadece kendisi için yorumlayıp kullanamaz, bilim insanı ortaya çıkabilecek bilginin çevre ve topluma yansımasını irdeleme ve sonuçları konusunda gerekli uyarıları yapma sorumluluğunu da taşır (TÜBA, 2002; 11-15). Bilim insanlığg bir yaşam biçimidir. Her şeyden önce bilim insanı kendini aşmış evrenselleşmiş kişidir. Bilim insanı kendine özgü bir yaşamsal disiplini olan, herkesten fazla toplumsal sorumluluk taşıyan, ülke ve bölge sınırlarını aşan, yeryüzünün her noktasında meydana gelen olayların kendisini de ilgilendirdiğini düşünen kişidir.

Bilim insanı kısaca bilgi üreten kişi olarak tanımlanabilmektedir. Bilim insanı araştıran kişidir. Araştırmada ise keşfetme tutkusu asıldır. Bu tutku öyle bir şeydir ki zaman kavramını ortadan kaldırmaktadır (Şahin, 2000). Akademisyenler yasaların öngördüğünden çok daha uzun saatler boyunca çalışmaktadır, çoğu kez masalarında ya da laboratuarlarında sabahlamaktadırlar. Akademisyenler öğrencileri yardım istediğinde onlara tatil günü olduğunu, onlara yardım edemeyeceklerini söyleyemezler (Rosovsky, 1994). Bilim insanları için zaman veya mesai kavramı kağıt üzerinde var olsa da aslında böyle bir durum yoktur. Bilim insanları sadece gündüzleri veya mesai saatleri içerisinde değil, gerekirse geceleri de çalışmaktadırlar. Bilim insanları için hafta sonu tatilleri de birikmiş işlerin tamamlanması için bir firsattır. Ayrıca bilimsel toplantılar da bilim insanlarının zamanlarının önemli bir kısmını almaktadır. Sonuçta ideal akademisyenliğin özellikleri arasında mesai kavramı ile kendilerini sınırlamamaları da gösterilmektedir. Bir akademisyenin günlük yaşantısının 
anlatıldığı, "Bir Dekan Anlatıyor" adlı kitapta, kitaba konu olan kişinin gündelik işine ayırdığı zaman yaklaşık olarak 12 saat sürmektedir.

Üniversiteler ilk kuruldukları tarihten bu yana bilgiyi arama ve dönüştürmeye adanmış özel yerler olarak düşünülmüştür. Akademisyenleri kamu hizmeti yapan diğer işgörenlerden ayıran temel özellik, mesleğin yerine getirilmesi sürecinde araştırma özgürlüğünden doğan ayrıcalıktır (Tural, 2003). Eğitim kurumlarına, işletmelerden farklı bir anlayışla bakmanın zorunluluğu ve üniversitelerin diğer eğitim kurumlarından, öğretim üyelerinin ise devletin kurumlarında çalışan diğer işgörenlerden farklılığı norm kadro çalışmalarının üniversitelerde uygulanabilirliğini zorlaştırmaktadır.

$\mathrm{Bu}$ çalışmada norm kadro çalışmalarının üniversitelerde uygulanabilirliği, yapılan uygulamaların zorluğu gibi konular ile ilgili olarak Ankara Üniversitesi Eğitim Bilimleri Fakültesi öğretim üyelerinin görüşleri alınmış ve şu sorulara yanıt aranmaya çalışılmıştır; "Yükseköğretim kurumlarında norm kadro çalışması yapılması hakkında ne düşünüyorsunuz?" "Yükseköğretim kurumlarında norm kadro çalışması yapılabilmesinin zorlukları neler olabilir?" "Yükseköğretim kurumlarında yapılacak olan norm kadro çalışmalarında sizce hangi ölçütler temel alınmalıdır?" "Kamu yönetimi reform tasarısında kurumun etkinliği ve verimliliğin artırılması için devlet kuruluşlarında norm kadro çalışmasının yapılması gereği belirtilmektedir. Siz de bu düşünceye katılıyor musunuz?" "Yükseköğretim kurumlarında norm kadro uygulamasıyla birlikte ne tür olumlu veya olumsuz gelişmeler olabilir?"

\section{YÖNTEM}

$\mathrm{Bu}$ bölümde araştırma deseni, evreni, örneklemi ve verilerinin toplanması konularında bilgi verilmiştir.

\section{Araştırma Deseni}

$\mathrm{Bu}$ çalışmada nitel araştırma tekniği kullanılmıştır. Çünkü, nitel araştırmalar, araştırma yapılan ya da yapılması planlanan kişilerin sahip oldukları deneyimlerinden doğan anlamların sistematik olarak incelenebilmesinde tercih edilen bir tekniktir (Ekiz, 2003). Nitel araştırma tekniklerinin doğal ortama duyarlılık sağlaması, araştırmacının katılımcı rolü olması, bütüncül bir yaklaşıma sahip olması, algıların ortaya konmasını sağlaması, araştırma deseninde esnekliği olması ve tümevarımcı bir analize sahip olması önemli özellikleridir (Yıldırım ve Şimşek, 2000). Bu bağlamda nitel araştırmalar, araştırmanın üretildiği sosyal bağlama duyarlılığ sağlamaktadır (Kuş, 2003). 


\section{Evren ve Örneklem}

Araştırmada amaçlı örnekleme yolu izlenmiştir. Amaçlı örnekleme yöntemleri tam anlamıyla nitel araştırma süreci içinde ortaya çıkmıştır. Amaçlı örnekleme zengin bilgiye sahip olduğu düşünülen durumların derinlemesine çalışılmasına olanak vermektedir (Yıldırım ve Şimşek, 2000). $\mathrm{Bu}$ örneklemede seçim için önemli olduğu düşünülen ölçütler belirlenmekte ve bu ölçütlere göre seçilen örneklemin, araştırma evrenini bütün nitelikleri ile temsil edebildiği düşünülmektedir (Tavşancıl ve Aslan, 2001). Bundan dolayı, çalışmada, amaca uygun bir örnekleme yoluna gidilmiştir. Buna göre görüşmeler, Ankara Üniversitesi Eğitim Bilimleri Fakültesinde görev yapan öğretim üyeleri ile gerçekleştirilmiştir. Görüşme yapılan kişiler Fakültede bulunan anabilim dalı başkanlarından ve yine Fakültede yapılmış olan norm kadro çalışmasında görev yapmış olan kişiler arasından seçilmiştir. Özellikle, norm kadro çalışması yapmış kişilerin görüşlerinin alınması bu süreç ile ilgili fikirlerin yansıtılması açısından önem taşımaktadır. $\mathrm{Bu}$ çalışma, norm kadro çalışmalarının Ankara Üniversitesi Eğitim Bilimleri Fakültesi öğretim üyeleri görüşleri doğrultusunda üniversitelerde uygulanabilirliğini tartışmaya açmayı amaçlamaktadır.

\section{Veriler ve Toplanması}

Bu çalışmada veri toplama yöntemi olarak yarı yapılandırılmış görüşme tekniği kullanılmıştır. Bu yöntem ne tam yapılandırılmış görüşmeler kadar katı ne de yapılandırılmamış görüşmeler kadar esnektir; iki uç arasında yer almaktadır (Karasar, 1995, 165). Araştırmacıya bu esnekliği sağladığı için yarı yapılandırılmış görüşme tekniği kullanılmıştır.

Araştırmada kullanılan soruların yanıtlarını bulabilmek amacıyla Ankara Üniversitesi Eğitim Bilimleri Fakültesinde görev yapan dokuz öğretim üyesiyle görüşmeler yapılmıştır. Görüşmeler ses kayıt cihazı ile kaydedilmiş ve daha sonra çözümlenmiştir. Öğretim üyelerinin görüşleri alınarak, öğretim üyelerinin norm kadro çalışmaları ve norm kadro çalışmalarının üniversitelerdeki uygulanabilirliği ile ilgili görüşleri ve bununla ilgili önerileri ortaya konulmuştur.

\section{BULGULAR}

Araştırma kapsamında, katılımcılar ile yapılan görüşmelerde beş temel soru yöneltilmiştir. $\mathrm{Bu}$ sorular, katılımcıların norm kadro çalışmalarının üniversitelerde uygulanabilirliğini, norm kadro çalışmalarının yararlarını ve zararlarını ve norm kadro çalışmalarının üniversitelerde uygulanmasının zorluklarını nasıl tanımladıklarını içermektedir. $\mathrm{Bu}$ çerçevede görüşme yoluyla elde edilen veriler "karşı olma-olmama" kategorileri aracılığıyla analize tabi tutulmuştur. Karşı olup-olmama kategorisi temelinde, tek tek dokuz katılımcıdan her birinin konuşmaları incelenmiş ve bu çerçevede "karş1, karşı değil ve ihtiyatlı" sözcükleri bu kategoriye ait kodlamalar olarak 
belirlenmiştir. İlk önce katılımcılardan her birinin bunlardan hangisini vurguladığına bakılmıştır. Katılımcılar görüşme sırasına göre; K1, K2, K3, K4, K5, K6, K7, K8 ve K9 olarak gösterilmiştir. Buna göre;

\section{Üniversitelerde Norm Kadro Çalışmaları}

K1: Norm kadro çalışmaları yararlıdır. Çünkü bazı bölümlerde ve bazı üniversitelerde aşırı derecede yığılmış kadrolar var.

K2: Üniversitelerde ya da diğer kamu kurumlarında norm kadro çalışması verimliliği artırabilir.

K3: Norm kadro çalışmasına geniş bir perspektiften bakıldığında olumlu bir çalışma diye düşünüyorum.

K4: Üniversitenin hesap verilebilirliği açısından da norm kadro yapilmalidir.

K5: Üniversitede norm kadro çalışması yapılmamalıdır.

K6: Kadroların verimli ve işlevsel kullanılması ve iyi değerlendirilmesi açısından yararlı olur diye düşünüyorum.

K7: Norm kadro çalışmalarını, yükseköğretim kurumlarında öğretim üyelerinin üzerinden yapmak zordur. Ancak esnek ölçütler ile yapılabilir.

K8: Özellikle yüksek öğretimde norm kadro çalışması çok zor olmakla birlikte, bir takım minimum standartların belirlenmesi açısından yararlı olduğunu düşünüyorum.

K9: Yüksek öğretim kurumlarında norm kadro çalışmalarının yapılabileceğine katılıyorum ve inanıyorum.

Karşı olup-olmama kategorisi açısından bakıldığında, katılımcıların sadece biri üniversitelerdeki norm kadro çalışmalarını olumlu bulmamakta, biri ölçütlerin esnek olması halinde uygulanabileceğini belirtmekte, diğer katılımcılar ise üniversitelerdeki norm kadro çalışmalarını yararlı ve uygulanabilir bulmaktadır. Ancak, karşı olup-olmama kategorisine ait olan kodlamaların her biri, acaba katılımcılar için aynı anlamamı gelmektedir? Diye sorduğumuzda karşımıza şöyle bir tablo çıkmaktadır.

SORU 1: Yükseköğretim kurumlarında norm kadro çalışması yapılması hakkında ne düşünüyorsunuz?

Araştırmaya katılan öğretim üyelerinden yedi tanesi norm kadro çalışmalarının üniversitelerde yapılması gerektiğini ve yararlı olduğunu, bir kişi norm kadro çalışmalarının üniversitelerde yapılmaması gerektiğini belirtmiştir. Araştırmaya katılanlardan bir kişi ise bu çalışmalara ihtiyatlı yaklaşmış ve aşağıdaki noktaları vurgulamıştır. 
K7: Norm kadro çalışmalarını, yükseköğretim kurumlarında öğretim üyelerinin üzerinden yapmak zordur. Üniversitelerde norm kadro akademik personel dışında rahatlıkla yapılabilir. Norm kadro çalışmaları akademik personele hata payını geniş tutmak koşuluyla uygulanabilir. Öğretim üyeleri diğer mekanik işlerde çalışan işgörenlerle karşılaştıramayız. Akademisyen mesai saatleri dışında da çalışan kişidir. Akademisyenlerde norm kadroya dahil olacaksa ölçütler biraz esnek olmalidir.

Araştırmaya katılan öğretim üyelerinden norm kadro çalışmalarını uygulanabilir olarak gören ve bu çalışmaların faydalı olabileceğini düşünenler aşağıdaki fikirleri ileri sürmüştür. $\mathrm{Bu}$ katılımcılar bu çalışmaların, örgütlerdeki kaynakların etkili ve verimli kullanılmasına yardım edeceğini de belirtmişlerdir.

K1: Norm kadro çalı̧̧maları yararlıdır. Çünkü bazı bölümlerde ve bazı üniversitelerde aşırı derecede yığllmuş kadrolar var. Bunların planlanması için yapılması iyidir.

K2: Üniversitelerde ya da diğer kamu kurumlarında norm kadro çalışması verimliliği artırabilir. İnsan emeğinin daha iyi kullanılması için gereklidir.

K6: Kadroların verimli ve işlevsel kullanılması ve iyi değerlendirilmesi açısından yararlı olur diye düşünüyorum.

K9: Ben, yüksek ögretim kurumlarında yapılan norm kadro çalışmalarının yapılabileceğine katıllyorum ve inanıyorum. Bir kurumun amaçlarının gerçekleştirilmesi, bu kurumun etkililiğinin ve verimliliğinin sağlanması, örgütler için en önemli hedeftir.

Araştırmaya katılan öğretim üyeleri norm kadro çalışmalarının üniversitelerde uygulanabileceğini belirtmesine rağmen, öğretim üyelerinin bir çoğu norm kadro çalışmalarının üniversitelerde uygulanması sırasında bir takım güçlüklerin olabileceğini belirtmişlerdir.

K4: Bu konuda çalışmış, görev yapmış biri olarak çok zorlandığımızı belirtmek isterim. Akademisyenler, bu kadar esnek çalışması gereken, aynı zamanda bu kadar da çok disiplinli çalışması gereken bir gruptur. $B u$ açıdan ya da bilimsel bakıldığında norm kadro ilk önce reddedilebilir. Norm kadro neye göre belirlenebilir, standart nasıl konulabilir. Akademik yaşamda esnek çalışma saatleri vardır, bir standardl yoktur, görünür bir ödülü de yoktur. Akademisyenlik kendisine özgü yönleri olan bir meslektir. Ancak yine de asgari müstereklerde birleşilerek bir ölçüt oluşturmak mümkündür. Üniversitenin hesap verilebilirliği açısından da norm kadro yapılmalıdır. Yapılması çok zor olsa da. 
K8: Özellikle yüksek öğretimde norm kadro çalışması çok zor olmakla birlikte bir takım minimum standartların belirlenmesi açısından yararlı olduğunu düşünüyorum. Tabii bu minimum standartların ne olmasının gerektiği çok yoğun ve katılımlı bir tartışmayı gerektiriyor... Yani akademisyenlik o kadar da keyfi ve başıboş bir süreç değildir. Akademisyenlerin bir de personel yanı vardır. Bir akademisyen yanımı var ve çalışan olarak, örgüte, öğrencilerimize vb. karşı sorumluluklarımı var. Bunların da belli minimum standartlarının oluşturulması gerektiğini düşünüyorum.

Katılımcılardan norm kadro çalışmalarının üniversitelerde yapılmaması gerektiğini düşünen katılımcı ise aşağıdaki görüşleri ileri sürmüştür.

K5: Üniversitede norm kadro çalışması yapılmamalıdır. Çünkü norm kadro çalışması gelecekteki etkinliklerin bilinmesi durumunda bu etkinliklerin gerçekleşmesi için ne kadar insana ihtiyaç duyulacağında belirlenebileceği varsayımından hareketle yapılıyor. Oysa üniversitedeki etkinlikler bu kadar önceden öngörülecek etkinlikler değildir. Çünkü üniversitelerde hizlı bir değişim yaşanmaktadır ve üniversiteler yeni işlevler üstlenmektedir.

Üniversitelerde norm kadro çalışması yapılamayacağını vurgulayan görüşmeci buna gerekçe olarak norm kadronun amacıyla üniversite işlevinin örtüşmemesini göstermiştir. Görüşmeci, üniversitenin zamanla değişen işlevlerinin norm kadro çalışmalarıyla belirlenip, tanımlanamayacağını belirtmiştir.

SORU 2: Yükseköğretim kurumlarında norm kadro çalışması yapılabilmesinin zorlukları neler olabilir?

Araştırmaya katılan öğretim üyelerinin büyük bir çoğunluğu yüksek öğretim kurumlarında uygulanacak olan norm kadro çalışmalarının bir takım zorlukları olduğunu belirtmişlerdir. Katılımcılar bu zorluklar içerisinde en çok akademisyenliğin kendine özgü özelliklerine vurgu yaparak, bu özelliklerin standartlaştırılmasındaki güçlüklere değinmişlerdir. Bununla ilgili olarak şu görüşleri belirtmişlerdir.

K1: Akademisyenlerin işi diğer memurların işsi kadar tekdüze değildir. Akademisyenlerin işlerini standartlaştırmak zordur.

K2: ... Görev tanımlarının içine akademik hayatın tamamı alınamaz. Alınamayan bu kısım nasıl değerlendirilecektir? Bu norm kadro çalışmalarının bir sorunudur. Bu tip zorluklar olmasına rağmen norm kadro çalışmaları akademisyenler için de yapılabilir. Ancak ölçütleri çok iyi planlanmış olması gerekir.

K4: Biz yaptığımız çalışmada bireysel farklılıkların en büyük zorluk olduğunu fark ettik. Ölçütteki hesaplama katsayılarının belirlenmesinde 
bu zorluğu yaşadık. Farklı anabilim dallarının kendisine özgü yönlerini yansitacak ortak bir ölçüt belirlenmesi çok zordu. Ancak yine de ortak noktalarda birleşilebilir.

K8: Insanlar arasindaki bireysel farklillklar bunun en büyük sebebi. Ödev okumak, sinav kağıdı okumak, araştırma yapmak, danışmanlık vb. çalışmalara ayrllan süre kişiden kişiye değişebilir. Performans ölçütlerinin konulmasını yani bir akademisyenin minimum performansinin ne olmasi gerektiği belirlenmeli ve bu performans norm haline getirilmelidir.

Araştırmaya katılan öğretim üyeleri, bu süreçte yaşanabilecek diğer sorunlar ya da zorluklar olarak da aşağıdaki görüşleri belirtmişlerdir.

K6: Birimler arası çekişmeler olur, sorun yaratır. Uzun dönemli ihtiyaçlar göz önüne alınmall, çok katı olmak yerine gerektiğinde esneklik tanınmall, yetkili kurulların da onayı ile birimler arası kadro aktarımı geçici olarak yapılabilmelidir.

K7: Insanların katılımını sağlamak gerekli. Her birimin işlevini tanımlamak, işin sınırını çizmek ve öğretim üyelerinin görev tanımını yapmak zordur...

K9: Aslında en büyük zorluk, yüksekögrretim kurumlarında norm kadro çalışmalarının yapılıp yapılmaması konusunun karara bağlanmasıdır. Çünkü bununla ilgili iki farklı görüs var. Birincisi üniversitelerde norm kadro çalışmalarının yapılamayacă̆ı ile ilgili, diğer görüş ise üniversitelerde norm kadro çalışmalarının yapılabileceği ile ilgilidir. Ben bu ikinci görüşe katıllyor ve norm kadro çalışmalarının gerekli olduğunu düşünüyorum. Karşı çıkanlar öncelikle öğretim üyesinin norm kadrosunun belirlenemeyeceği düşüncesini ileri sürmektedir. Norm kadro çalışmalarının yapılmasında bu çok önemli bir engeldir.

Katılımcılardan norm kadro çalışmalarının üniversitelerde yapılmayacağını ileri süren katılımcı ise şu görüşleri belirtmiştir.

K5: ... Norm kadro "stratejik planlama kapsamında düşünülebilecek kısmi bir planlama çalışmasıdır. Bu tür teknikler işletmelerden çıkmıştır. Issletmelerde geleceğe ilişkin öngörüler daha kolaydır ve bu da doğaldır. İsletmelerde norm kadro çalışması kolaylıkla yapılabilir. Iş̧letmelerde esnek bir kadro planlaması yapılabilir. Daimi kadrolar için norm kadro yapılırken diğer geçici kadrolar için esnek olabilir ve bunlar için norm kadro yapılmayabilir. Ancak üniversiteler için böyle bir şey yoktur böyle bir zorunluluk da yoktur zaten.

Norm kadro çalışmalarının üniversitelerde uygulanamayacağını savunan katılımcı, üniversitenin bir işletme olmadığını bu durumun 
üniversitelerde norm kadro çalışmaları yapılabilmesini engellediğini ve en büyük zorluğun bu farklılıkta yattığını belirtmiştir.

SORU 3: Yükseköğretim kurumlarında yapılacak olan norm kadro çalışmalarında sizce hangi ölçütler temel alınmalıdır?

Araştırmaya katılan öğretim üyelerinin hemen hemen tamamı, üniversitelerdeki norm kadro çalışmalarında, kullanılacak olan ölçütleri belirlemenin çok zor olduğunu belirtmişlerdir. Bununla ilgili görüşler şunlardır:

K3: ...Norm kadronun hangi kriterlere göre belirleneceği konusunda slkıntılar var. Bunun için akademik işgörenlerin kriterleri tartışılmalıdır. $\mathrm{Bu}$ ölçütler fakülte düzeyinde değil üniversitede bir çerçeve oluşturulmalıdır. Bu demektir ki böyle bir çerçeve çizilebilir...

K4: Ölçütü belirlemek çok zor. Ancak zorluğa rağmen norm kadro çalı̧̧maları yapılmalıdır. Her fakültenin norm kadro kriterleri farklı, kendine özgü olmalıdır. Ölçüt olarak, ilk önce akademisyenlerin neler yaptığ belirlenmelidir. Benzer konular birleştirilmelidir. Yasal şartlar göz önünde bulundurulmalıdır.

K6: Temel ölçüt ilgili birimin gelecekle ilgili gelişme tasarılarını, öngörülerini almall, buna göre kadro belirleme yoluna gidilmelidir. Elbette ki genelin içindeki konum ve durum da göz önüne alınmalıdır. Norm kadroda esas olan bugün değil, 20-30 yll sonrasıdır daha çok.

K7: Sübjektif değerlendirme yapllabilir. Özellikle tecrübeli yönetici ve akademisyenlerden yararlanılmalıdır. Her bir bölüm hatta her bir birim, ölçütler geliştirmelidir.

K8: Kesinlikle, çünkü düzey açısından bakmak çok önemli. Bir kere lisans-lisansüstü ayrımı yapılmalıdır. Sosyal bilimler-fen bilimleri, uygulamall alanlar-teorik alanlar olarak da bakılabilir. Bu yolla zorluklar aşılabilir. Performans kendi içinde düşünüldü̈̆̈̈ zaman zorluklar aşılabilir. Bu anlamda iş analizi ve görev tanımları çok önemlidir. Fakülte içindeki farklı bölümlerin farklı özellikleri göz önünde bulundurulmalıdır. Yapılan iş temel alınmalıdır.

K9: Kurumun amaçları çözümlenmelidir. Örgüt çözümlemesi yapılmalıdır. Örgüt amaçlarının geçerliği tartışılmalıdır. Örgüt yapısının uygunluğu tartışılmalıdır. Örgütte amaçları gerçekleştirmek için kurulmuş olan yapı yeterli sayıda ve nitelikteki insan ile destekleniyor mu? Bunun belirlenmesi gerekir. Bu noktalar çok önemlidir. Bunun devamında da hizmetin standardı ortaya konulmalıdır. Eğitim kurumları kar amaçlı kurumlar değildir. Bunun için de ayrılan kaynakların etkili ve verimli kullanılması gerekir. Bu ülkenin ekonomisi açısından ve kurumun amaçlarına ulaşması açısından da gereklidir. 
Katılımcılardan norm kadro çalışmalarının üniversitelerde uygulanamayacağını belirten katılımcı, Norm kadro çalışmalarında her hangi bir ölçüt olacak değişkenlerin bulunmadığını belirtmiştir.

SORU 4: Kamu yönetimi reform tasarısında kurumun etkinliği ve verimliliğin artırılması için devlet kuruluşlarında norm kadro çalışmasının yapılması gereği belirtilmektedir. Siz de bu düşünceye katılıyor musunuz?

Araştırmaya katılan öğretim üyeleri norm kadro çalışmalarının devlet kurumlarında etkinliği ve verimliliği artırıp artırmayacağı ile ilgili soruya genellikle olumlu yaklaşmışlar ve etkinliği ve verimliliği artırabileceğini belirtmişlerdir.

K1: Norm kadro çalışmaları kurumların etkililiğini ve verimliliğini artırabilir. Norm kadro çalışmaları uzun dönemli yapılmazsa bazı bölümlerde (emeklilik, işten ayrılma vb. nedenlerle) akademisyen azalması olabilir. Bu da bölümlerin verimliliğini düşürür.

K3: Norm kadroya sadece sayı ile ilgili yada işgörenlerin bir yerden bir yere gönderilmesi ile ilgili değilse etkin ve verimli olabilir. Kurumun kendine yeniden bakmasl, kurumun kendisine yakın ve uzak vadede planlar yapması açısından, insan kaynaklarını yeniden yapılandırma çerçevesi içinde düşünen bir yaklaşım olarak olumlu tarafları vardır. Ĕger norm kadronun belirlenmesine belli ilkeler çerçevesinde yaklaşılırsa bunların (akademik ve idari işgören) adil ve etkin dağılımı konusunda olumlu sonuçlar üreteceğini düşünüyorum.

K7: Türkiye'de kurumlar hesapsız ve plansız biçimde büyüdüler. Aynı kurum içinde benzer işleri yapan birimler, birbirinden habersiz kurumlar oluştu. Aynı işlevleri yapan kurumların oluşması sonucunda kurumlarda yeni bir yapılandirmayl beraberinde getirmiştir. Bu durum üniversiteler için de geçerlidir. Mevcut yapıyı sorgulamak ve çözümlemek için bir çalışma yapılmalı. Bu çalışma norm kadroda olabilir...

K9: Norm kadro çalışmaları kurumların etkili ve verimli bir şekilde çalışmaları için gerekli olan çalışmalardır ve ben bu amaca hizmet edeceğine de inanıyorum. Ancak eğitim kurumları kar amaçlı kurumlar değildir. Bunun için de ayrılan kaynakların etkili ve verimli kullanılması gerekir. Bu ülkenin ekonomisi açısından ve kurumun amaçlarına ulaşması açısından da gereklidir.

Katılımcılar norm kadro çalışmalarına üniversite özerkliği açısından da yaklaşmışlar ve aşağıdaki görüşleri belirtmişlerdir.

K2: Norm kadro çalışmaları özerk üniversite ruhuna çok da aykırı değildir. Çünkü kadroları yine üniversiteler kendileri belirleyecektir. 
Dışarıdan kadro dayatılacağına inanmiyorum. Kadroların elde edilmesinde kolaylık sağlayacağına inanıyorum, bu yolla aşırı kadro şişkinlikleri de önlenebilir. Çalışanlar daha verimli ve etkin çalışabilir.

K4: Norm kadro çalışmaları kadro taleplerinin dayană̆ı olabilir. Kadro standartları oluşursa aşırı büyümenin de önüne geçilebilir.

K5: Norm kadro özerkliği şu anlamda zedeleyebilir. İhtiyaçların belirlenmesi, üniversitelerin kendi kurullarınin karar vermesi durumunda isek norm kadro bir kere yapıldiğ l ve daha sonra emirler yukarıdan geldiği için, üniversite özerkliği zedelenebilir...

K8: Üniversite nerede özerk ki bu konuda özerkliği zedelensin. Norm kadro yapmayarak özerk olamayız, değiliz de zaten. Üniversite özerkliği için ilk önce yönetsel özerklik olmalıdır. Bizde mali özerklik ve akademik özerklik de yok zaten. Üniversitenin bu kadar önemli özerklik problemleri varken norm kadronun tek başına bir özerklik sorunu yaratacağını hiç düşünmüyorum.

K9: Özerkliği zedeleyeceğini düşünmüyorum. Bu tip çalışmalar tüm örgütler için gereklidir. Norm kadro çalışmalarının örtük amacı kamu kurumlarında daralmaya gitmek olabilir. Çünkü bu politika 1980’li ylllardan beridir var. Ancak bunu bilmek zordur... Tüm örgütlerde mutlaka norm kadro yapılmalıdır. Üniversite özerkliğine aykırı da değildir. "Üniversiteler özerktir, istediği kadar kişiyi istihdam eder" diyemeyiz. Çünkü eğitim kurumlarl için bütün kurumların işgören, derslik, ögrenci sayılarının en uygun büyüklükte olması ve bunların da standartlarının belirlenmesi gerekir.

Norm kadro çalışmalarının uygulanamayacağını ileri süren katılımcı bu konuda aşağıdaki görüşleri belirtmiş̧ir.

K5: Üniversitelerde de insangücü planlaması yapılmalıdır. Ancak bu planlamada verimlilik ölçütlerinin kullanılması ne derece anlamlıdır, bu tartışılabilir. Çünkü akademik çalışmanın ya da akademisyenin verimliliğini ölçmek o kadar da kolay değildir. Bunda makale sayısı ya da yabancı makale sayısı kullanılabiliyor. Ancak bu niteliğin göz ardı edilmesidir. Aslında nitelikli bilgi üretmeye dönük çalışmalara bakmak lazımdır. Bunlarda ciddi bir jüri değerlendirmesi yapılamayacağına göre (performans ölçmek için) bu tamamen kafada oluşmuş, işletmelerden geçmiş performans değerlendirme ile yapılmaktadır. ... Nitelik ölçütleri öne çıkarılmalıdır. Nitelik öne çıkarıldığında hep süreç gündeme gelir. Süreci sayısallaştıramazsınız. Ĕger bunu yaparsanız ölçmüş sayılmazsınız. Nitelik önemlidir. 
SORU 5: Yükseköğretim kurumlarında norm kadro uygulamasıyla birlikte ne tür olumlu veya olumsuz gelişmeler olabilir?

Araştırmaya katılan öğretim üyeleri norm kadro çalışmalarının üniversitelerde uygulanmaya başlaması ile birlikte ortaya çıkabilecek olumlu veya olumsuz gelişmeler konusunda, genellikle norm kadro çalışmalarının esnek olması gerektiğine vurgu yapmaktadır. Buna göre aşağıdaki görüşleri belirtmişlerdir.

K1: Norm kadro çalışmaları esnek olmalıdır. Akademisyenlerin azaldı̆̆ bölümlerde ders azalacă̆ için yük artarken araştırma azalabilir. Bu durum bölümü hoca açısından dışa bağımlı hale getirebilir...

K3: Üniversitelerin kendine özgü yönleriyle esnetildiği çalışmalar gereklidir. Öyle ki üniversite içindeki farklı fakültelere göre değişebilecek, esnek, genelden özele inen ulusal bir planlamadan daha yerel bir planlamaya hatta fakülte/okul düzeyine kadar inen bir boyutu olacak...

K8: Ĕ̆ger çok katı bir norm kadro çalışması içine girilirse, esneklik koyulmazsa, uzun vadeli planlamalar yapılmazsa örgüt kendini kapatmış ve gelişme olanağını kısıtlamış olur. Ayrıca kurumsal talepler ile yapılan norm kadro çalışmaları paralel olmalıdır. Bu yapılmazsa norm kadro kisitlayıcı, engelleyici ve değişmeyi engelleyici bir rol oynayabilir.

Norm kadro çalışmalarının olumlu yönleri olarak katılımcılar aşağıda yer alan görüşleri belirtmişlerdir.

K2: Norm kadro çalışmalart ile gelecek için etkin bir planlama yapılabilir. Bu olumlu bir yöndür.

K4: Norm kadro çalışmaları kadro taleplerinin dayanağı olabilir. Kadro standartları oluşursa aşırı büyümenin de önüne geçilebilir. Norm kadro komisyonları uzun vadeli çallşmalı ve kriterleri objektif olarak ortaya koymalıdır. Norm kadro iyi işlenirse yararı olur...

K6: Kadroların etkili, verimli, işlevsel kullanımı yönünde olumlu bir nitelik taşlyabilir. Ama yüksekögretim kurumları sürekli gelişme içinde olmalıdır ve bu kurumlarda ögrenci sayısı giderek artmaktadır.

K7: Üniversiteler norm kadro yoluyla kendine çeki düzen vereceklerdir. Belki bu sorgulama sonucunda amaçlar tekrar gözden geçirilecektir. Bu durum da yeni yapılanmalara gidilecektir.

K9: Yüksek öğretim kurumlarının etkililiği ve verimliliğini artıracaktır. Kurumsal kaynakların etkili ve verimli kullanılmasını sağlayabilir.

Norm kadro çalışmalarının olumsuz yönleri olarak katılımcılar aşağıda yer alan görüşleri belirtmişlerdir. 
K4: ...Norm kadro çalı̧̧malarında objektif kriterler konulmazsa zararlı olabilir. Akademisyenler benim bölümüm, benim konumum diye hareket ederlerse zararı olur. Norm kadro kriterleri belki akademik anlamda iyi işlemeyen bölümleri de çalıştırabilir.

K6: Ĕger norm kadro diye çok katı / sıkı bir uygulama benimsenirse bu kurumların gelişmesi durur. Kurumlar ihtiyacı karşılayamaz duruma düşer. Bu nedenle hem uzun dönemli hem de esnek ve gelişmelere açık bir uygulama benimsenmelidir.

K7: Norm kadro mevcut durumdan hareket ediyor, fakat üniversiteler sürekli değişen bir yaplya sahiptir. Statik bir durumdan devingen bir kurumla ilgili çalı̧̧ma yapmak olumsuz bir gelişme olarak gösterilebilir. Bu durum yükseköğretim kurumlart için olumsuz bir durum doğurabilir.

K9: Norm kadro çalışmaları sürekli olarak güncellenmesi ve yeni koşullara uyarlanması gereken çalışmalardır. Üniversiteler sürekli olarak değişen kurumlar olduğundan bu çalışmaların esnek olması gerekir. Ĕger bir kere yapllırsa, esnek olmazsa, ileride problemler yaşanabilir. Norm kadro çalışmaları üniversitede akademik ve idari işgören sayısının azaltılmasina ve iyi işlemeyen ya da amaca hizmet etmeyen bölümlerin de kapatılmasına yol açabilir.

K5: ... Illeride norm kadro sayısının belirlenmesine yönelik ölçütler dayatılabilir ve sayıları buna göre belirleyin denilebilir. Böyle bir şey olamaz. Akademik etkinliklere göre bir insangücü planlaması yapılabilir. Ancak bunun için ilk önce akademisyenlere güvenilmelidir. Performans değerlendirme şirket mantı̆̆ına uygundur.

\section{TARTISSMA, SONUÇ VE ÖNERILER}

Kaynakların etkin ve verimli kullanımı ekonomik bir yaklaşım olarak şirketlerde uygulanmaya konulmuştur. Bu doğrultuda toplam kalite, kalite çemberleri, performans değerlendirme ve norm kadro gibi bakış açıları geliştirilmiştir. $\mathrm{Bu}$ yaklaşımlar eğitim kurumlarında da uygulanmaya koyulmuştur. $\mathrm{Bu}$ yaklaşımlardan norm kadro çalışmaları önce okullarda sonra da üniversitelerin gündemine oturmuştur.

Norm kadro çalışmalarının üniversitelerde uygulanabilirliğini tartışmak amacıyla yapılan bu çalışma sonucunda tartı̧̧maya katılan öğretim üyeleri norm kadro çalışmalarının üniversitelerde uygulanabileceğini belirtmişlerdir. Görüşmeciler norm kadro çalışmalarıyla kaynakların etkin ve verimli kullanımının sağlanması, kadro talebine haklı gerekçe gösterme yollarının açılması, benzer işlevleri gören birimlerde tekrarlardan kaçınılması ve üniversitelerin kendisini sorgulamasının sağlanacağı belirtilmiştir.

Üniversitelerde norm kadro uygulaması yapılırken bir takım zorluklarla karşılaşılacağı görüşmeciler tarafından vurgulanmıştır. Görüşmeciler 
akademik personelin görev tanımının yapılmasının ve fakülteler-bölümler hatta anabilim dalları arasındaki farklılıkların bu çalışmayı zorlaştıran etkenler olarak göstermiş̧lerdir. $\mathrm{Bu}$ zorlukları aşma yolu olarak geniş katılımlı bir çalışma ve her fakültenin kendi ölçütlerini geliştirme gösterilmiştir.

Araştırmaya katılan öğretim üyeleri norm kadro ölçütlerinin ne olması doğrultusunda spesifik öneriler getirememişlerdir. Sadece ölçüt geliştirirken fakülteler arasındaki farklılıkların ve üniversitenin işlevlerinin göz önünde tutulması gerektiğini belirtmişlerdir. Araştırmaya katılan bir görüşmeci ise üniversitelerin bir işletme olmadığını bu nedenle işletme mantığıyla üniversite yönetilemeyeceğini vurgulayarak norm kadro çalışmalarının üniversitelerde uygulanamayacağını belirtmiştir.

Üniversitenin işlevlerinin diğer eğitim kurumlarından farklı olması, üniversite işgörenlerinin görev tanımlarıyla ilgili net bir sınır çizilememesi, norm kadro çalışmanın üniversitelerde uygulanabilirliğini zorlaştırmaktadır. Üniversitelerde norm kadro çalışması yapılması yasal bir zorunluluk olarak üniversitelere dayatılacaksa bu çalışma geniş katılımlı bir zeminde tartışılarak norm kadro ölçütleri belirlenmelidir. Farklı kurumlara benzer ölçütleri uygulamanın zorlukları bulunmaktadır. Türkiye Yükseköğretim Sistemi incelendiğinde üniversiteler arasında farklılıklar olduğu görülmektedir. $\mathrm{Bu}$ farklılıklar dikkate alınmadan geliştirilecek ölçütler çalışmalardan elde edilmek istenen faydayı engelleyecektir. Norm kadro çalışmaları üniversitelerde uygulanacaksa bu farklılıkların tespit edildiği geniş katılımlı bir yöntem izlenmelidir.

$\mathrm{Bu}$ çalışma sonucunda norm kadro çalışmalarının üniversitelerde uygulanabilirliği ile ilgili bir takım görüşler ortaya çıkarılmıştır. Görüşlerde üniversitelerde norm kadro çalışmaları yapmanın ve sürecin zorluklarına ilişkin görüşler de belirtilmiştir. Teorik olarak norm kadro çalışmalarının her türlü örgütte uygulanabileceği öngörülmüş̧ür. Ancak sonuçlardan da görüldüğ̈̈ gibi, norm kadro çalışmalarının üniversitelerde uygulanmasının bir takım zorlukları vardır. Buna göre, araştırmacılara, norm kadro çalışmalarının üniversitelerde uygulanmasında kullanılacak ölçütler ile ilgili araştırmalar, bu çalışmanın nicel araştırma yöntemleri ile de yapılması önerilebilir.

\section{KAYNAKLAR}

Acar, H. (2000). Milli Eğitim Bakanlığına bağlı eğitim kurumlarında yönetici ve öğretmenler bakımından norm kadro uygulaması ve Ankara Üniversitesi Eğitim Bilimleri Fakültesi mezunlarının istihdam sorunları. Ankara Üniversitesi Ĕ̈itim Bilimleri Fakültesi Dergisi, 1-2, 53-66.

Acar, H. (2001). Milli Eğitim Bakanlığına bağlı eğitim kurumlarında yönetici ve öğretmenler bakımından norm kadro uygulaması. Eğitimde 
yansımalar: IV. 2000 yılında Türk Milli Eğitim örgütü ve yönetimi. Ankara: Öğretmen Hüseyin Hüsnü Tekışık Eğitim Araştırma Geliştirme Vakfi Yayınları.

Ekiz. D. (2003). Eğitimde araştırma yöntem ve metotlarına giriş. Ankara: Anı Yayıncilı.

Kalkandelen, H. (1997). Örgütlerde yeniden yapılanma ve norm kadro. Ankara: Anı Yayıncılık.

Kamu Kurum ve Kuruluşlarınca Yapılacak Norm Kadro Çalışmalarında Uygulanacak Usul ve Esaslar (2000/1658 SK, 06.11.2000) Resmi Gazete, 20.12.2000, Say1: 24266,

Kamu Kurum ve Kuruluşlarınca Yapılacak Norm Kadro Çalışmalarının Tamamlanmasına İlişkin Takvim (2001/39 Sayılı Genelge). Resmi Gazete, 11.07.2001Sayı: 24459.

Karakütük, K. (2002). Öğretim üyesi ve bilim insanı yetiştirme. Ankara: Anı Yayıncilık.

Karakütük, K. (Komisyon Başkanı ve Diğerleri) (2003). Ankara Üniversitesi Eğitim Bilimleri Fakültesi norm kadro komisyonu çalışması. Ankara: Komisyon Raporu. XV+227 s.

Karasar, N. (1995). Bilimsel araştırma yöntemi. Ankara: 3A Araştırma Eğitim Danışmanlık.

Kuş, E. (2003). Nicel-nitel araştırma teknikleri. Ankara: Anı Yayıncılık.

Ortaş, İ. (2002). Bilim, bilim insanı ve bilimsel etik. Üniversite Ve Toplum Dergisi, 2, www.universite-toplu.org. İndirme Tarihi: 15.02.2003.

Rosovsky, H. (1994). Üniversite bir dekan anlatiyor. (Çev: S. Ersoy). Ankara: TÜBİTAK Yayınları.

Şahin, Ş. (2000). Bilim insanı yetiştirme politikaları. Cumhuriyetimizin 75. Yllında üniversitelerimiz sempozyumu bildirileri. 18-19 Eylül 1998. (Edt: F. Adamdan). İstanbul: Boğaziçi Üniversitesi Yayınları.

Tavşancıl, E. ve Aslan, E. (2001). İçerik analizi ve uygulama örnekleri. İstanbul: Epsilon Yayıncilık.

TÜBA. (2002). Bilimsel araştırmada etik ve sorunları. Ankara: Türkiye Bilimler Akademisi Yayınları.

Yıldırım, A. ve Şimşek, H. (2000). Sosyal bilimlerde nitel araştırma yöntemleri. Ankara: Seçkin Yayıncılık.

Yükseköğretim Kanunu (2547 SK, 04.11.1981). Resmi Gazete, 06.11.1981, Say1: 17506. 


\section{SUMMARY}

Norm staff studies are made in order to make organizations do their duties actively and productively. One of the most important aims of these studies is, to determine the quality and number of needed staff for executing the duties. For this purpose in norm staff studies, the needed ideal staff for carrying out the duties in organizations is defined in qualitative and quantitative view. Norm staff studies are being tried to adapt to universities as other oublic foundations. But, universities differ from other public foundations by the charecter they have. The main reason of this difference is the hardness in determining the norm staff of academicans comparing to public foundations' staff. Because, it is impossible to limit the studying hours by working hours for this reason, it is necessary to define the difficulties that can be faced in foundations where lecturers work. For this purpose in this study, interviews were held with lecturers who made norm staff study or evaluated a study made before.

\section{Problem}

Norm staff is the arrangement of the structure according to aim in known type that allows carrying out the duties which are formed by quality a like duties in an organizations. In norm staff arrangements, quality a like duties must be sequenced according to the principle of organic development, and of possible it must be written after the classification in itself (Kalkandelen, 1997).

It was mentioned that norm staff studies has a great contribution to organizations. Acar (2000) was summarized the contributions of norm staff studies as: Norm staff studies will make the sources be used suitably and generously, studies will provide reaching modern norms. Norm staff studies will provide opportunity and chance parity and contribute to democracy process; it also will provide the evaluation of workers that is going to suit the objective fair, qualified, generous and economic needs.

In recent years, it is going to be tried to make norm staff studies in universities. But, there are some difficulties in the process taken in continuing the norm staff study in universities. In other words, it does not seem to be easy do make norm staff study in universities like other foundations. Because, universities have some properties that belong to itself and the academicians who work in universities have different working conditions from other workers.

In this study, the opinions of lecturers from Ankara University, Educational Sciences Faculty were taken about the subjects as adaptation of norm staff study to universities and the difficulties of applications made. 


\section{Method}

In this study, qualitative research technique was used. Because, qualitative researches are the technique that preferred in systematic examination of meanings from the experience of persons interviewed or planned to be interviewed (Ekiz, 2003). In this context qualitative researches provides the sensitively of social connection of research produced (Kuş, 2003).

In this research, purposive sampling pathway was carried out. Purposive sampling methods were come out with the process of qualitative research. Purposive sampling allows a deep study of the situations that are thought to be having rich knowledge (Yıldırım \& Şimşek, 2000). Because of this, in the study, aim suitable sampling was selected. According to this, interviews were held with Ankara University, Educational Sciences Faculty lecturers.

In this study, semi-structured interview technique as data collecting method was used. This method is neither firm as full-structured interviews, nor elastic as non-structured interview; it is between these two edges (Karasar, 1995, 165). Because of the elasticity to researcher, semi-structured interview technique was used.

In order to find the answers of the questions in the research, interviews were held with nine lecturers of Ankara University, Educational Sciences Faculty. Interviews were recorded with voice recorder and then analyzed. The opinions of lecturers about norm staff study, the adaptations of norm staff study to universities and their suggestions were taken.

\section{Findings}

Five main questions were asked to interviewers in the research's area. These questions consists of the interviewers' point of view about the adaptation of norm staff studies to universities, useful and harmful sides of norm staff studies and difficulties in adaptation of norm staff studies to universities. In this sides of view, datas obtained by interviewing were analyzed by "to be against-or not" categories. According to "to be against-or not" category's basic, the speeches of nine interviewers each were examined and the codes "against, not against, prudent" were determined for this category. Firstly it was examined that which code the each interviewers mentioned about. Interviewers were shown as I1, I2, I3, I4, I5, I6, I7, I8 and I9 according to interview order. According to this:

\section{Nom Staff Studies in Universities,}

I1: Norm staff studies are useful. Because there are over ranged staffs at some departments and some universities. 
I2: Norm staff studies in university or other public foundations can increase the productivity.

I3: When looked at a wide perspective, I think norm staff studies are positive.

I4: Norm staff study must be carried out for the accountability of universities.

I5: Norm staff studies mustn't be held at universities.

I6: In my point of view, it is going to be useful in using the staffs productively and functional.

I7: It is difficult to apply norm staff study on lecturers, but it can be done by elastic criterions.

I8: Especially, it is hard to make a norm staff study in graduate education, but I think, it is useful for determining some minimum standards.

I9: I agree and believe in that norm staff studies can be held in graduate education foundations.

When we look from the "to be against or not" categories side, only one of the interviewers thought norm staff studies at universities isn't positive, one of them mentioned that it could be applied with elastic criterions, the other interviewers found the norm staff studies useful and applicable. But, it is impossible to say that the codes of "to be against-or not" category had the same meaning for all interviewers each.

\section{Results and Discussions}

This study was made for debating the applicability of norm staff studies to universities and as a consequence, lecturers attended to research mentioned that norm staff studies could be made at universities.

The interviewers told, there were some difficulties that could be faced while the norm staff study was applied. The solution for getting rid of these difficulties was the self-criterions of faculties. The interviewers could not prove specific suggestions about what the norm staff criterions must be.

The difference in functions of university from other educational foundations and lack of clear limitations make the norm staff study's application difficulty to universities.

Whether, norm staff study is going to be a formal compulsory for universities, this study must be debated by a wide attendance and norm staff criterions must be determined. There are difficulties in adapting like criterions to different foundations. When Turkish Graduate Education System was examined differences between universities were seen. The criterions developed without taking care of this differences, will interrupt the 
advantages expected from the study. If norm staff study is going to be applied to universities, these differences must be retained with a wide attendance.

As a consequence of this study, some opinions were carried out about the applicability of norm staff studies to universities. There were ideas about the difficulty in making norm staff studies at universities and the process. It was foresighted that norm staff studies could be applied to every foundation. But, as seen from the results that, there are some difficulties in applying norm staff study to universities. According to this, that can be suggested to researchers that, qualitative research methods can be used in determining the criterions of norm staff study adaptation to universities. 